\title{
Licensed professions: a new look at the association between social origins and educational attainments in Italy
}

\author{
Lucia Ruggera ${ }^{1}$
}

Accepted: 26 February 2021 / Published online: 19 April 2021

(c) The Author(s) 2021

\begin{abstract}
It has long been known that Italy is characterized by the highest levels of professional regulation in Europe, but little attention has been given to the link between professional regulation and educational stratification. This article investigates the association between social origins and education by focusing on fields of study within tertiary education and by disaggregating the upper class of social origin into different micro-classes of professionals. Thus, since these professions are regulated in the first place by educational fields of study, it assesses how processes of social closure enhance occupational intergenerational immobility in the professional employment in Italy. Recently, deregulation of liberal professions in Italy has been central in many public and political debates. It contributes to these debates by examining the micro-level dynamics in the professionals' social reproduction and related practises of social exclusion, which may have strong implications for policy interventions. By using ISTAT's "Sbocchi Professionali dei Laureati" survey (2011), and employing multinomial logistic regressions, it shows how social selection into highly regulated fields of study is guided by parents' professional domain. The analyses indicate that both sons and daughters of licensed professionals are more inclined to graduate in a field of study that is in line with the father's profession and that this propensity is stronger among children of regulated self-employed professionals.
\end{abstract}

Keywords Professional closure $\cdot$ Educational inequalities $\cdot$ Micro-classes $\cdot$ Fields of study · Italy

\section{Introduction}

This article aims to investigate processes of social closure at the top of the occupational hierarchy, in Italy. It focuses on the social reproduction of regulated professional groups by disaggregating both social class of origin and educational attainments into horizontal dimensions. Indeed, since these professions are regulated in the first place by educational fields of study, their social immobility comes to light evidently by considering into details

Lucia Ruggera

lucia.ruggera@utu.fi

1 Department of Social Research, University of Turku-Sociology, Assistentinkatu 7, 20014 Turku, Finland 
the association between social origin and education. Recently, deregulation of liberal professions in Italy has been central in many public and political debates. This article contributes to these debates by examining the micro-level dynamics in the professionals' social reproduction and related practises of social exclusion which may have strong implications for policy interventions.

It has been long acknowledged that inequality of educational opportunities is prevalent in many Western countries. Social advantages are largely reproduced and handed down from parents to children through education (Blau \& Duncan, 1967; Blossfeld \& Shavit, 1993; Breen, 2004; Bukodi \& Goldthorpe, 2018; Werfhorst \& Luijkx, 2010). Indeed, social class also affects which educational paths students choose, with children from more advantaged backgrounds enrolling in academic fields of study and children from lower social origins enrolling in vocational programmes (Gamoran, 2001; Gamoran \& Mare, 1989). Fields of study at the tertiary education are relevant to the process of social stratification as well (Barone \& Schizzerotto, 2011). Professionals are the largest group at the top of the occupational hierarchy, and their children display disproportionately greater likelihood of remaining in the upper class (Breen \& Muller, 2020). Moreover, according to the Ruggera \& Barone (2017), market-entry regulation is associated to the level of social reproduction of professional groups in various European countries. Since Italy has one of the highest levels of professional regulation in Europe and given the persistent and high level of social immobility at the top of the occupational hierarchy (Barone et al., 2010), understanding the processes behind professionals' social reproduction is crucial. Only a few studies attempted to study educational and occupational social mobility of professional groups in Italy (Ruggera, 2016); and, most of them are professions-specific studies (Pellizzari \& Orsini, 2012; Chiesi 1997); and little attention has also been paid on gender differences (e.g. Checchi, 2010). Thus, a clear lack in the literature concerns micro-class occupational social reproduction in the professional employment in Italy.

According to Grusky (2005), social class action often takes place at the occupational, rather than at the big-class level (Grusky \& Sørensen, 1998; Grusky \& Weeden, 2001; Weeden \& Grusky, 2005). Occupational groups are responsible for the institutionalization of the structure of work and ultimately for the system in which people are educated in preparation for the professional world (Jonsson et al., 2009). This is clearly the case with licensed professions, ${ }^{1}$ for which access to occupations is regulated, first, by field of study. For such credentialized fields, a system of skills, aspirations, and cultural background acquisition is actively created and maintained, and hence, it institutionalizes a particular stratification (Grusky \& Sørensen, 2001). Most of the literature on social mobility and educational inequalities has looked at the effect of parents' social class in a vertical dimension and children's fields of study (e.g. Werfhorst \& Luijkx, 2010).

This article analyses how horizontal educational processes through which occupations, or more specifically, professions, are intergenerationally reproduced. It differentiates between regulated and unregulated professionals who operate in different fields in an attempt to underline how social selection into various fields of study is guided by a parent's professional domain. Following social closure theory (Murphy, 1988; Parkin, 1979), it argues that professional regulations have also significant implications for educational inequalities within tertiary education. Moreover, by considering specific patterns

\footnotetext{
1 In this context, the term licensed professions refers to highly regulated professions that are organized in professional associations, and that require a mandatory license in order to practice a given set of exclusive tasks (i.e. lawyers, notaries, doctors, architects, engineers).
} 
of association between fathers' professions and sons' and daughters' educational fields of study, it highlights how the transmission of occupation-specific resources in the regulated professions promotes their chances of social immobility at the top of the occupational ladder.

\section{Why children of professionals might aspire to become professionals themselves}

To understand how social origin affects children's educational field of study, it is worth considering recent developments in class theory stressing the fact that class action takes place at the occupational level; consequently, the study of social mobility cannot be limited to an analysis of educational attainments that are hierarchically structured, either explicitly or implicitly (Grusky \& Sørensen, 1998; Grusky \& Weeden, 2011). According to Grusky (2005) professionals are an exemplar case of how intergenerational reproduction operates at the level of occupations because it involves occupation-specific resources. Four different types of resources are considered: cognitive, social, cultural, and economic resources.

Firstly, a natural starting point is the standard argument that professional families transmit cognitive abilities that pay off principally in the professional class (Goldthorpe, 2002). The ability to write effectively, for example, is useful in many professional occupations and is presumably inculcated in children of professionals because their parents stress the importance of reading; frequently discuss newspapers and other written material at home; and at times, even provide hands-on instruction in writing (Weeden \& Grusky, 2012). When considering professional groups, this transmission of knowledge concerns more concrete occupation-specific abilities and skills (e.g. vocabulary of medical terms with a Latin root specifically employable in medical field occupational positions). For example, engineers may bring home building construction models; architects can focus on drawing parks or houses with their children, and so on.

Secondly, children growing up in professional families are exposed to professional networks that may have a similar reproductive effect. They come into frequent contact with other professional families, through whom they learn about the professional world and orienting themselves in relation to that world. They also learn how to prepare for professional occupations and have a ready supply of contacts that can assist them as they begin their careers (Jonsson et al., 2009). Of course, the more structured a profession is, as in the case of a law firm, the more they rely on social networks to facilitate the social reproduction of the professional class.

Thirdly, economic (liquid) resources can be exploited by children of professionals to secure professional educational credentials at broader level. When self-employed professionals, at micro-class level, are taken into consideration, this transmission also concerns fixed resources, such as a dentistry practice and the related client-portfolio (Grusky, 2005). Obviously, a purely economic mechanism does not tell us why children of professionals might aspire to become professionals; however, it does speak to why, once such aspirations are in place, they are especially likely to be put into practice (Bourdieu, 1974, 1986).

Finally, the children of professionals are exposed to a wider class culture that likewise prepares them for professional destinations (i.e. abstract argumentation). But, again, it becomes much clearer when a specific profession is taken into consideration. According to Jonsson et al. (2009), professional cultures are formed and maintained in the presence of two key conditions: a training regimen that inculcates a set of values and way of life 
and occupational closure processes that ensure that professionals interact principally with one another. Lawyers, for example, undergo intensive training in law school and frequently interact with one another in a relatively closed workplace (i.e. closure conditions), thus creating and sustaining a very specific occupational culture. ${ }^{2}$

This discussion helps to clarify why professionals' children are more likely to assume professional positions than non-professional positions of equivalent standing (Weeden, 2002). If following a rational choice theory, specifically relative risk aversion hypothesis (Breen \& Goldthorpe, 1997), educational choices reflect the endeavour to avoid social demotion, then the safest strategy for children of professionals to ensure that goal is to rely on the competitive advantages associated with their parents' occupations-specific resources. Children from working-class families, on the other hand, who are more likely to compare the probability of success with the costs associated with specific educational choices, are less likely than children of professionals to pursue a higher education in a credentialized field of study (Gambetta, 1987; Goldthorpe, 2002; Gamoran, 2001; Breen \& Yaish, 2006).

Both of these theories focus on the micro-dynamics of professionals' social reproduction which become evident by employing a micro-class approach (Grusky, 2005). This approach entails an analytical shift from a quantitative to a qualitative study of family resources available to children. A micro-class analysis also allows for the investigation processes of social closure that magnify the importance of occupation-specific resources (Murphy, 1988; Parkin, 1979; Weber, 1922). Closure theory is predicated on the assumption that social groups can and do act to further their collective economic interests (Sørensen, 1996, 2000; Sørensen \& Grusky, 1998). Furthermore, recognition of the rewards of occupational collective action may be scattered among the membership (Grusky $\&$ Weeden, 2005). In many occupations, the collective action function has been centralized and institutionalized in the form of professional associations (Grusky, 2005). These social groups, formed around occupational positions in the division of labour, construct and defend social and legal boundaries in order to benefit from professional closure (Weeden $\&$ Grusky, 2001). Closure secures advantages for professionals at the expense of other groups, whose members do not have access to the profession (Sørensen, 1996). Such exclusion, based on any convenient or visible characteristics, such as race and gender, is being replaced by exclusion based on "individualistic" criteria, such as educational credentials and knowledge (Collins, 1979; Bourdieu, 1977, 1979; Abbott, 1988). Educational credentialing refers to the use of familiar symbols or markers of knowledge (e.g. a degree in the pharmaceutical field) conferred by formal educational institutions to monitor entry into occupations (Collins, 1971, 1975). It has been argued that credentials can restrict labour supply in two ways (Weeden, 2002). On the one hand, educational credentials certify the acquisition of skills and competencies, and as a result, any restrictions on opportunities to attain these credentials will shrink the pool of candidates who have the capacity to perform key occupational tasks (Larson, 1977; Parkin, 1971, 1974; Sørensen, 1996). Policymakers, in turn, support credentialing as a necessary device for ensuring the quality of service providers. On the other hand, educational credentials are only loosely, not strictly related

\footnotetext{
2 As Grusky (2005) stresses, not all occupations have well-developed training regimens and dense intraoccupational networks of this sort, but professional groups seem to be an illustrative case of occupational reproduction, in which closure conditions are implied.
} 
to the knowledge a person needs in order to be competent at practising a particular profession (Grusky \& Weeden, 2001, 2011). Instead, these credentials could serve as a cultural currency establishing one's membership in a specific status group (Bourdieu \& Passeron, 1977; Parkin, 1979). Since educational credentials lead to a licensed system, largely enforced through norms and behavioural rules, they are a means used of restricting access to a profession by excluding candidates who have not met a particular set of criteria (Collins, 1979).

\section{Declining hypotheses}

As previous studies have demonstrated when, the origin-destination association is analysed from a comparative perspective, it becomes apparent that professionals' social reproduction is a deeply pervasive phenomenon; it is prevalent in Germany and Denmark (Ruggera \& Barone, 2017). In Italy, although professional regulation is even stricter than it is in Germany, occupational specificity levels are comparable (Ruggera, 2016). Market-entry professional regulations ranges from "zero" for non-licensed professions in the scientific fields 3 or in social sciences ${ }^{4}$ to "moderate" for technical professions to "elevated" level for pharmacists, doctors, and notaries (Patterson et al., 2003). Because closure varies across professions, this paper differentiates between professional groups so as to highlight to which the extent of their social reproduction is an expression of professional closure. Moreover, according to the social closure theory, social selection based on ascribed characteristics has been superseded by more individualistic criteria, such as educational credentials. Although women and men are analysed separately, I expect that both sons and daughters of professionals being encouraged to follow into their fathers' footsteps (see Ruggera, 2016). The social reproduction of licensed professionals beings with graduating from one specific field of study (single entry-route professions). Accountants are an exception. Accountancy is one of the few professions dual entry-routes professions ${ }^{5}$; degrees in both economics and law can be used as credentials to enter this specific profession.

H.1a: For credentialized fields (single entry-route professions), sons, and daughters of parents in a specific micro-class of professionals tend to graduate into the same professional domain of their fathers (e.g. medicine, pharmacy).

H.1b: Sons and daughters of accountants (dual entry-route profession) have a higher propensity to graduate in law and economics.

When considering children of larger entrepreneurs and higher managers (meso-classes within the upper class), it has been shown that prefer fields that equip them with specific

\footnotetext{
3 Two exceptions have to be pointed out in the scientific professions: actuaries who count for less than $2 \%$ and chemists who constitute are less than $8 \%$ (ILFI). These are the only two licensed professions that cannot be considered representative of this field.

4 Within social sciences profession, there is just one licensed profession. Psychologists accounts for less than $8 \%$, indeed they are not representative of this professional group (ILFI). Moreover, they are represented by a professional association within a licensure system since 1989. Moreover, the level of regulation is not high, because they do not perform exclusive tasks (since psychiatrists perform these tasks with exclusivity).

5 Notary profession is a dual entry routes profession as well, but considering the restricted number of notary seats in Italy is not possible to analyse them with survey data. It is therefore clubbed with the legal profession and its practitioners, such as lawyers and judges.
} 
economic or administrative skills and knowledge (Breen \& Jonsson, 2000; Werfhorst, 2002). Indeed, the upper class children are more inclined to graduate in law and economics as channels to transmit opportunities in life; however, further steps after graduation to enter a specific profession (after compulsory training and state examination) regard lawyers and accounts, and not larger entrepreneurs or higher level managers (Jackson, 2008). Thus, one cannot expect that their propensity to graduate in economics and law to be as high as that of lawyers and accountants.

H.2: Children of larger entrepreneurs and higher managers are more inclined to graduate in economics and law.

According to the theory of occupational closure, the social reproduction of professionals implicitly stimulates processes of social exclusion (Sørensen, 2000; Weeden, 2002). On the one hand, stringent entry restrictions enhance the competitive value of the cognitive, social, and cultural resources transmitted by the family of origin; on the other hand, they make investing in training for these professions extremely costly and risky for outsiders. Here, outsiders are defined as children of the lower social classes, as well as children from other sub-classes within the upper class who do not belong to a specific professional group.

H.3: Children of all other social classes (including children of higher managers and larger entrepreneurs) are less inclined to graduate into credentialized fields than children with a specific professional background (single entry-route professions).

Finally, only a few handful studies have considered the intergenerational transmission of professional business and clients portfolios. According to Pellizzari \& Orsini (2012), intergenerational class reproduction of these professionals is particularly widespread among professionals such as lawyers, notaries, and architects (Santoro, 1998; Tousijn, 1987). However, these studies are profession specific; in other words; they do not allow for a comparison between different professional groups. Some other studies on intergenerational mobility of self-employed professionals in Italy compare the meso-classes, but the results are controversial (Barbagli \& Schizzerotto, 1997; Fabbri \& Rossi, 1997; Schizzerotto, 1993). By employing to a micro-class approach, however, it is possible to go into details of the transmission of professional practices, thus acknowledging the dynamics of intergenerational mobility, which linked to both property and professional closure.

H.4: Micro-class and field of study affinities are more pronounced when the parents are self-employed professionals.

\section{Data, variables, and methods}

To test the hypotheses, I employed ISTAT's "Sbocchi Professionali dei Laureati" survey (27.868 observations). It was run in 2011 and targeted university graduates who had obtained their degrees four years prior to the survey. The procedure to collect these data is based on a stratified sample: from a random selection of municipalities to a random selection of universities within each municipality. It included information on the vertical and horizontal dimensions of educational attainments, information on parents' educational 
level and parents' occupational position ${ }^{6}$ (including differences in their employment conditions). The survey also supplied background information on high school, including types of schools attended and final grades, as well as demographic information (place of birth, age, gender, and nationality). Since the survey is about graduates' employment, an implicit sample selection is present. No information on the wider population is included. Thus, it must be kept in mind that results from the analysis are only inferable to Italian graduates. As a vast body of literature on the inequality of education has shown, in Italy, upper class' offspring are more likely to graduate than their socioeconomically disadvantaged peers (Barone, 2005, 2011). Moreover, in order to consider credentials that provide access to licensed professions, we have to take into consideration Masters' degrees. ${ }^{7}$

The outcome variable, concerning fields of study, is specified through a ten category classification, including: the humanities (clustered with, philosophy, literature, etc.); scientific fields (including chemistry, natural science, physics, maths, and so on); veterinarian clustered with pharmaceutical science; architecture; engineering; medicine; health science (expect medicine including professional nurses, etc.); law; social and political science; and economics. ${ }^{8}$ This classification partially differs from the one used in other academic studies $^{9}$ (Hansen, 1997; Stocké, 2007). Indeed, the main emphasis is on highly regulated fields of study that give access to specific professions (Chiesi, 1997). The explicative variable, social class of origin, is measured at the aggregated and disaggregated levels. ${ }^{10}$ Father's social class refers to the labour market-specific position occupied by the father when the respondent was 14 years old. Detailed information on mothers' occupational positions are not provided. This limitation mostly concerns daughters' labour market outcomes. However, according to institutional assets (e.g. male-bread winner model) and the advantages related to regulated professions in Italy, fathers' professional position is expected to be relevant for daughters' labour market outcomes as-even if at a broader class level (e.g. Ruggera \& Barone, 2017). At the aggregate level, commonly used to study the origin-education relationship, social origin corresponds to Erikson and Goldthorpe's (1992) class scheme: higher service class I, including: higher entrepreneurs, higher managers and high level professionals; low service class II; skilled white collars (IIIa); routine non-manual (IIIb); selfemployed with no or few employees (IVab); farmers (IVc); skilled and unskilled manual working class (V-VI-VIIab). At the disaggregate level, social origin also considers eight additional micro-classes of professionals, specifically classified as: professionals in scientific fields, such as physicists, chemists, mathematicians, geologists; architects; engineers; professionals in the life sciences, pharmacists and veterinarians; medical doctors; legal professions (lawyers, judges ${ }^{11}$ and notaries); professionals in economics, including

\footnotetext{
6 The occupation of the father has been taken into consideration in this paper and has been provided an occupational code-CP2011. CP2011 differs from ISCO-code in terms of occupational specifications. It includes five digits (not all of them are provided by ISTAT), but it allows specifying professional groups since the second and the third digits which are employed in the analyses.

7 Therefore, another sample selection is implied. Looking at these graduates, we are considering students who are motivated and/or bright.

8 Table A1 shows distributions of frequencies of the outcome variable (Online Appendix-Section 1).

9 In which fields of study were shown to be a relevant predictor of labour market performance.

10 Table A2 shows distributions of frequencies of the explicative variables (Online Appendix-Section 1).

11 The robustness of the analyses has been confirm by employed binary logit regressions for each field of study, and then by comparing binary coefficients with the multinomial coefficients. $T$ test for coefficients of the explicative variable at occupational level are provided in the Online Appendix-Section 2.
} 
accountants ${ }^{12}$; and professionals in social and political sciences, also including psychologists. Another specification of micro-classes of professionals concerns self-employed fathers. It includes fathers who are self-employed architects, engineers, lawyers, accountants, doctors, pharmacists, ad veterinarians.

The control variables used are gender; geographical areas (North East, North West, Centre, South, and Islands); age; nationality; secondary educational path and grades; and the father's education (vertical dimension). ${ }^{13}$

Since the outcome variable is categorical, multinomial logistic regression models were employed separately for men and women (reference category is "humanistic fields"). In Model 1 (men) and Model 2 (women), the main effect ${ }^{14}$ concerning big-classes and mesoclasses within the higher service class is calculated (reference category is the "working class"). Model 3 and Model 4 also include control variables. Main effects concerning professionals micro-classes are calculated in Model 5 (for men) and Model 6 (for women). Model 7 and Model 8 add control variables to Model 5 and Model 6. Model 9 and Model 10 take into consideration the father's employment situation for male and female population, respectively. These last two models are supplementary specifications of Model 7 and Model 8. As reported above, control variables include geographical areas, nationality, age, parental education, type of school, and grades.

I present average marginal effects (AME henceforth) of the explicative variable, and exploit their easier interpretability in terms of average differences in probability of graduation from a field of study across different classes, calculated in percentage points ${ }^{15}$ (Pisati, 2003). Results are displayed in a graphic form to enable easy interpretation of the coefficients. $^{16}$

The analytic strategy consists of three main steps. First, big-, meso- and micro-classes AME are compared in order to assess the heuristic value of the two different approaches. Second, gender differences are considered at both meso- and micro-levels. Finally, father's employment condition is used as an additional specification of the horizontal association between origin-education.

\section{Models and results}

Figure 1 displays results for medicine and pharmacy and veterinarian. These results test hypotheses 1a. In the case of medicine, AME are significant for the meso-class of professionals (12.7 and 11.9 percentage points, respectively, for men and women). As demonstrated in the lower part of the graph, this is due to the propensity of graduates, who are the sons and daughters of doctors, to follow into their fathers' footsteps (AME are 31.9 and 27.7 percentage points, respectively). The same affinity is also very strong for

\footnotetext{
12 Considering graduates in ILFI survey (a longitudinal survey on Italian families) reveals that accountants fathers in the professional group of economics constitute more than $85 \%$ of this group; that fathers who are pharmacists and veterinarians are more than $70 \%$ in the life science group; and that fathers who are lawyers, judges and notaries are more than $75 \%$ in the legal professions. Information on State exams and licensing allow us to deduce the number licensed professionals in the first occupation.

13 Distributions of frequencies are presented in Table A3 and Table A4 (Online Appendix-Section 1).

14 Main effects are included in the appendix in tabular form (Online Appendix-Section 2).

15 AME reflect the probability of graduating from a field due to a marginal change in the explicative variable of interest, keeping all the other variables constant.

16 AME and standard errors are presented in tabular form in the Online Appendix-Section 2.
} 


\section{Big- and meso-classes}
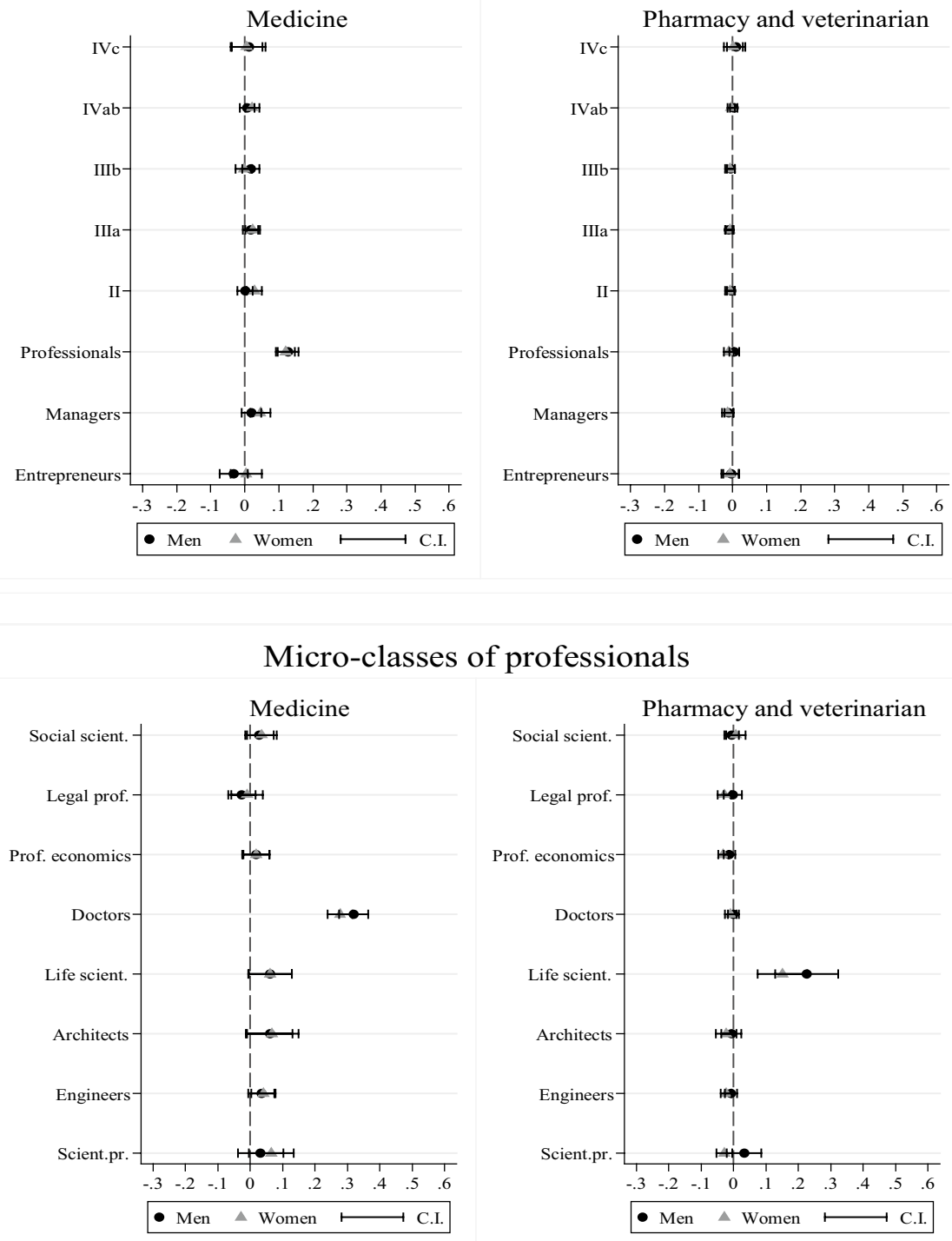

Fig. 1 AME from a multinomial logistic regression model for addressing probability of graduating in medicine, pharmacy, and veterinarian according to gender and big-, meso-classes, and micro-classes of professionals (ref. cat. working-class V-VIIab). Estimates are at net of controls (age, parental education, nationality, geographical areas, type of high school, high school grades). Black dots denote the AME of social classes for men, and the grey triangles denote AME of social class for women. Black lines denote $95 \%$ confidence intervals. Legend: white collars (IIIa), routine non-manual workers (IIIb), petite bourgeoisie (IVab), farmers (IVc). Source: ISTAT- Sbocchi Professionali dei Laureati (2011) 
the pharmaceutical and veterinarian professions (AME 22.6 and 15.2 percentage points, respectively, for men and women). For pharmacy and veterinarian, and medicine, the O-E affinity is very specific and huge. Whit respect to pharmacy and veterinarian, the magnitude of their effect at micro-class level is completely obscured when employing a big-class scheme.

Figure 2 displays the results for economics and law. These results test hypotheses $1 \mathrm{~b}$ and 2. In economics, AME are significant for the sons of larger entrepreneurs and high managers (respectively, 7.5 and 6.5 percentage points), but gender differences are significant only
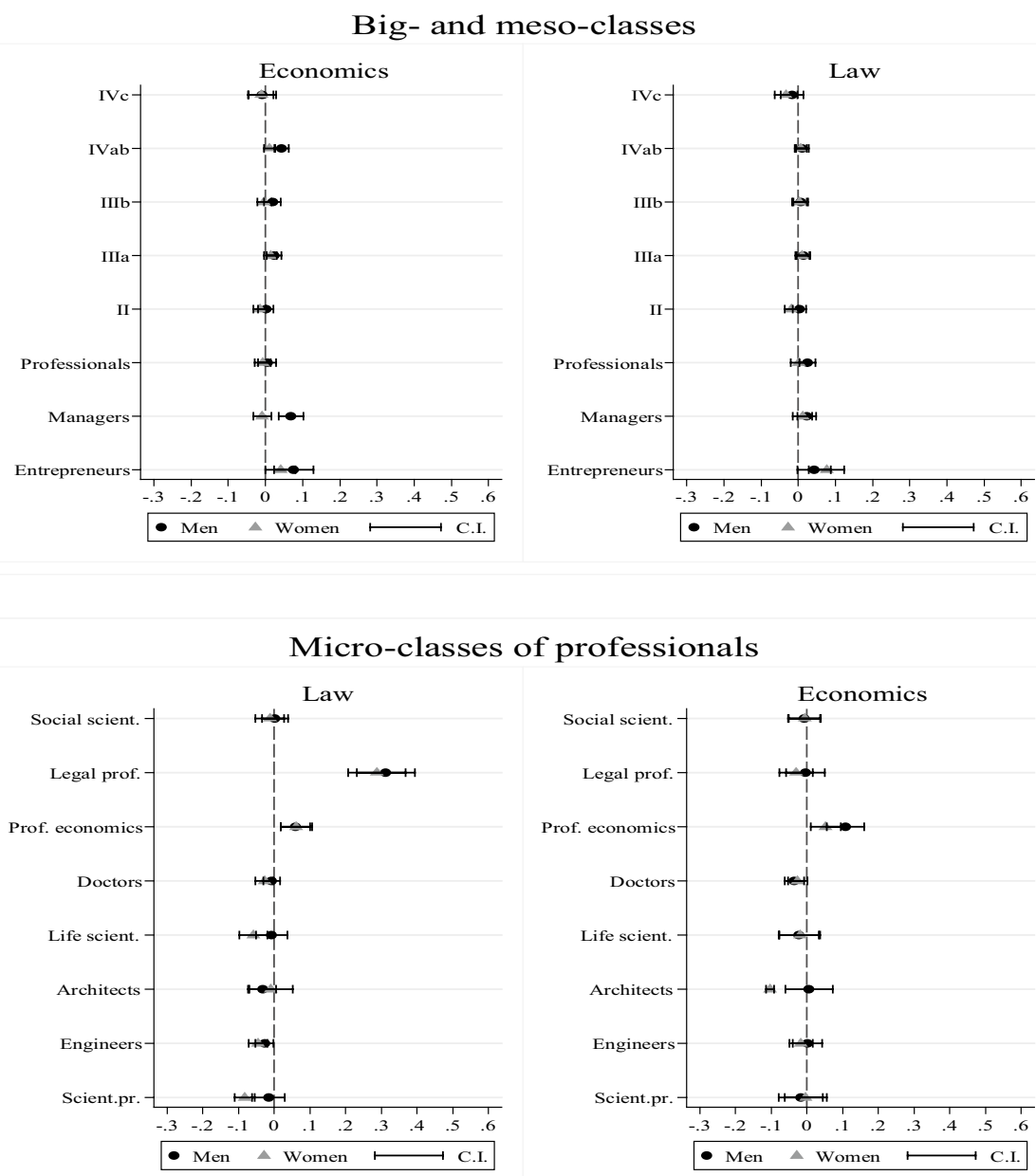

Fig. 2 AME from a multinomial logistic regression model for addressing probability of graduating in economics and law according to gender and big-and meso-classes, and micro-classes of professionals (ref. cat. working-class V-VIIab). Estimates are at net of controls (age, parental education, nationality, geographical areas, type of high school, high school grades). Black dots denote the AME of social classes for men, and the grey triangles denote AME of social class for women. Black lines denote $95 \%$ confidence intervals. Legend: white collars (IIIa), routine non-manual workers (IIIb), petite bourgeoisie (IVab), farmers (IVc). Source: ISTAT-Sbocchi Professionali dei Laureati (2011) 
for children of higher managers. Daughters of higher managers are less inclined than sons to graduate in economics, whereas the role played by property is important for men as it is for women. When law is taken into account, AME is significant for daughters of higher entrepreneurs (7,6 percentage points). AME for professionals at the meso-level-men as well as women - are not significant in both fields of study.

However, this pattern changes according to micro-classes, thus allowing hypothesis $1 \mathrm{~b}$ to be tested. Among graduates, both sons and daughters of professionals in economics are inclined to graduate in economics as well as in law (AME 10.8 and 5.3; and AME 5.9 and 6.2, respectively). In order to inherit the professional business of their parents, children of accountants can enter the profession by using both these fields of study as credentials. Thus, children of this specific professional group can choose to graduate with a law degree, which they can capitalize on once they join the labour market. Nonetheless, to go into details of career trajectories of these professionals, we also need to consider the occupational destination of children. When law is taken into account, the specific microclass affinity rises to 31 percentage points for men, and 29 percentage points for womenlawyers are a single route profession (hypothesis 1a). Moreover, men and women show very similar propensities. These results, again, are in line with the social closure theory: the higher is the level of occupational closure, the lower are gender inequalities within micro-classes, even when entry barriers are considered (Murphy, 1988). The transmission of occupation-specific resources, linked to professional closure and the related advantages, such as career stability, or economic rewards linked to the lower level of internal competition.

Figure 3 displays results for engineering and architecture which are in line with hypothesis 1a. It displays a positive propensity for daughters and sons of the lower service class to graduate in architecture, whereas a negative propensity to graduate in engineering is found for sons of professionals and managers. When it comes to micro-dynamics, affinities within a specific professional domain become relevant. Sons and daughters of architects are more inclined to graduate with a degree in architecture. Moreover, children of architects are also inclined to graduate in engineering; this result can be linked to the cultural proximity of these two fields of study. When considering engineering, instead, the effect of having a father as an engineer is more relevant for women than it is for men.

This result can be also linked to the gender composition of engineering, as shown in Table 1. Indeed, taking into consideration the gender composition of technical professions, architecture is more gender balanced than engineering (only 19\% are women). These results are in line with those of Checchi (2010). However, engineering is a more comprehensive field of study than architecture (see Chiesi, 2008). On the one hand, the magnitude of AME for the micro-class affinity for engineering is smaller than it is for architecture (see Table 1). On the other hand, children of engineers are significantly inclined to graduate in both architecture and engineering. Vice versa, children of architects are not inclined to graduate in architecture.

In Fig. 4, the cluster of more comprehensive fields, specifically scientific fields, social sciences, and health sciences (except medicine), is considered. ${ }^{17}$ Non-credentialized fields of study are more open: no specific patterns emerge from micro-classes of professionals. This confirms hypothesis 3. Sons and daughters of higher managers and professionals are less inclined to graduate from a scientific field than children of the working class. Moreover, this negative propensity is significant for daughters of larger entrepreneurs. These

17 Results of Model 3 and Model 4, as well as Model 7 and Model 8 are presented and compared (see the Online Appendix). 
Big- and meso-classes
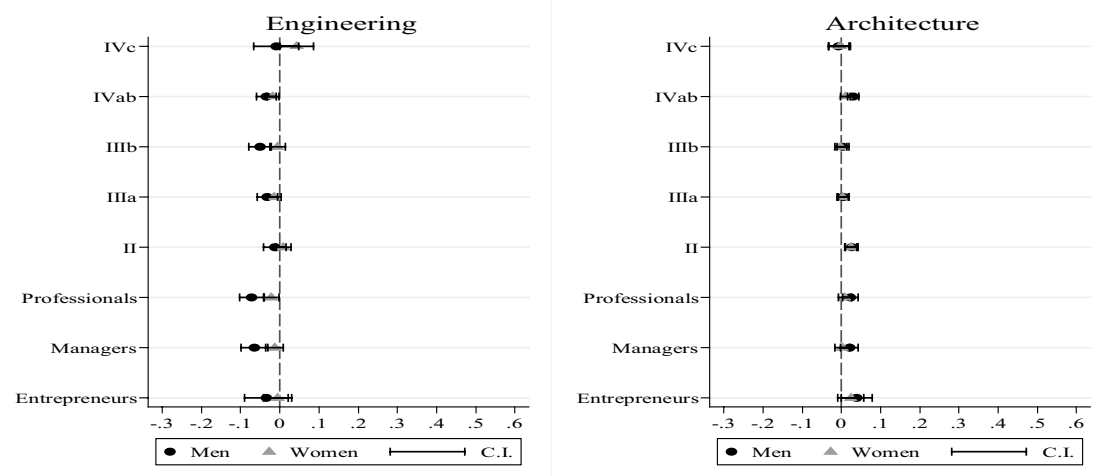

Micro-classes of professionals
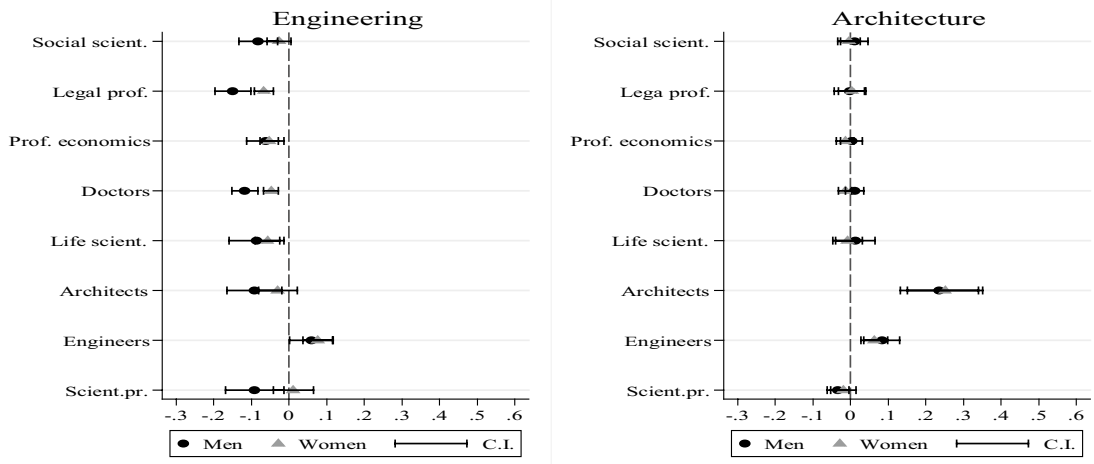

Fig. 3 AME from a multinomial logistic regression model for addressing probability of graduating in engineering and architecture according to gender and big-and meso-classes, and micro-classes of professionals (ref. cat. working-class V-VIIab). Estimates are at net of controls (age, parental education, nationality, geographical areas, type of high school, high school grades). Black dots denote the AME of social classes for men, and the grey triangles denote AME of social class for women. Black lines denote $95 \%$ confidence intervals. Legend: white collars (IIIa), routine non-manual workers (IIIb), petite bourgeoisie (IVab), farmers (IVc). Source: ISTAT- Sbocchi Professionali dei Laureati (2011)

results are in line with those of Ruggera (2016). A positive effect for social origins is found for son and daughters of higher managers, and daughters of routine non-manual class (IIIb). Daughters of larger entrepreneurs demonstrate a negative propensity to graduate

Table 1 Gender composition of engineering and architecture and related summary of AME for the affinity between micro-class of origin and graduates' field of study

\begin{tabular}{lllllll}
\hline Field of study & Male $\%$ & Female $\%$ & Tot. $\%$ & Tot. Abs & Male AME & Female AME \\
\hline Architecture & 46.9 & 53.1 & 100 & 1854 & $23.6^{* * *}$ & $25.1^{* * * *}$ \\
Engineering & 19.1 & 80.9 & 100 & 4042 & $5.9 *$ & $7.7^{* * *}$ \\
\hline
\end{tabular}

ISTAT_-"Sbocchi Professionali dei Laureati”

Significance: $<0.001 * * *<0.05 * *<0.10 *$ 


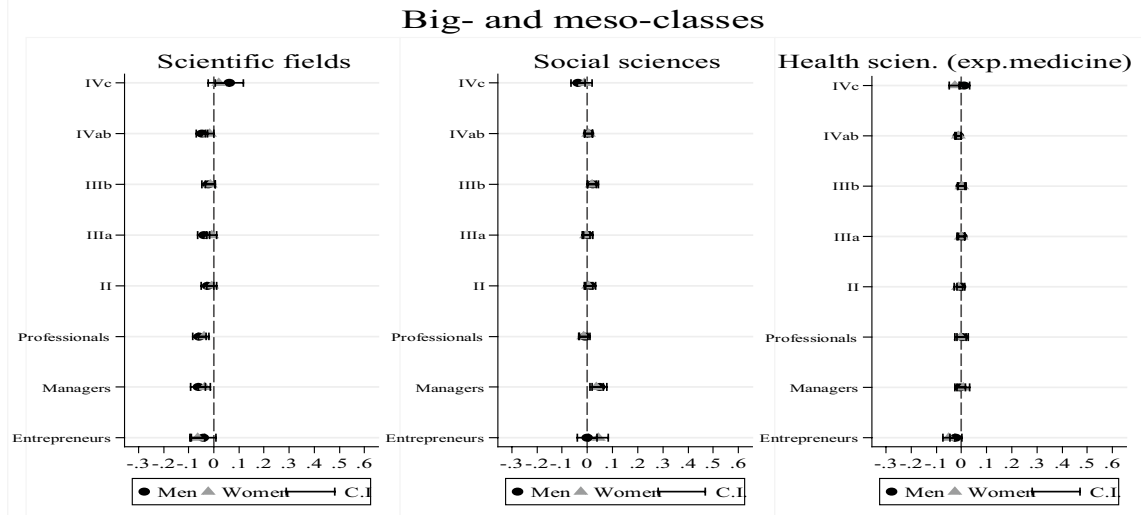

Micro-classes of professionals
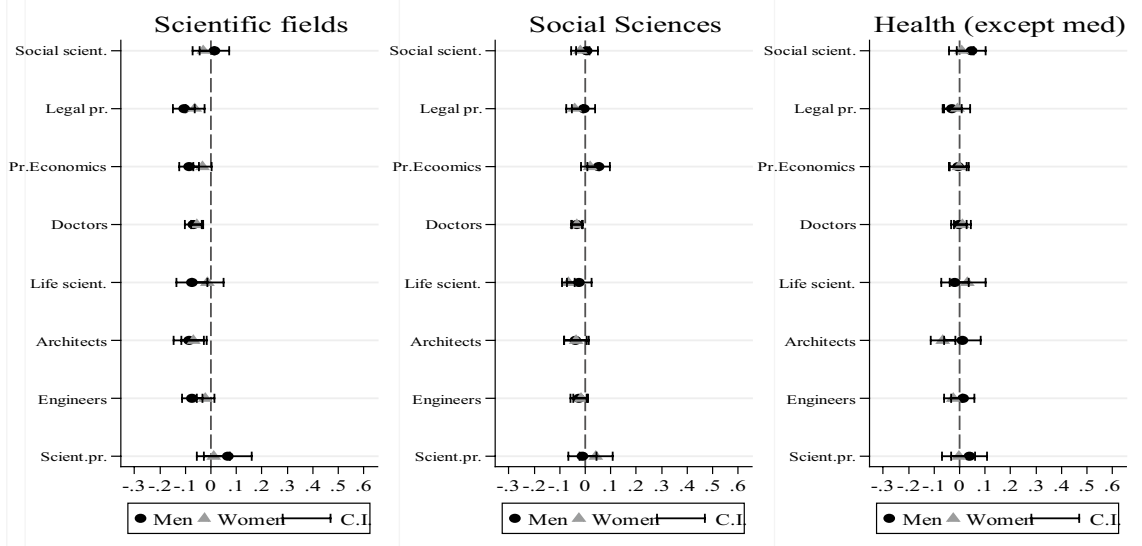

Fig. 4 AME from a multinomial logistic regression model for addressing probability of graduating in scientific fields, social sciences and health sciences (except medicine) according to gender and big-and mesoclasses, and micro-classes of professionals (ref. cat. working-class V-VIIab). Estimates are at net of controls (age, parental education, nationality, geographical areas, type of high school, high school grades). Black dots denote the AME of social classes for men, and the grey triangles denote AME of social class for women. Black lines denote 95\% confidence intervals. Legend: white collars (IIIa), routine non-manual workers (IIIb), petite bourgeoisie (IVab), farmers (IVc). Source: ISTAT- Sbocchi Professionali dei Laureati (2011)

in health sciences (except medicine). These results are in line with previous research on origin-education association, particularly with regard to women's choices of fields of study (Barone, 2011). As in Fig. 4, there are no significant AME among various micro-classes of professionals, except for the low likelihood of children of medical doctors, architects, professionals in economics, and law to graduate with degrees in a scientific field of study. These results emphasize the higher profitability of regulated professions with respect to unregulated professions. Indeed, as discussed in the theoretical framework, occupationspecific resources transmission encourages children of professionals to follow in their 


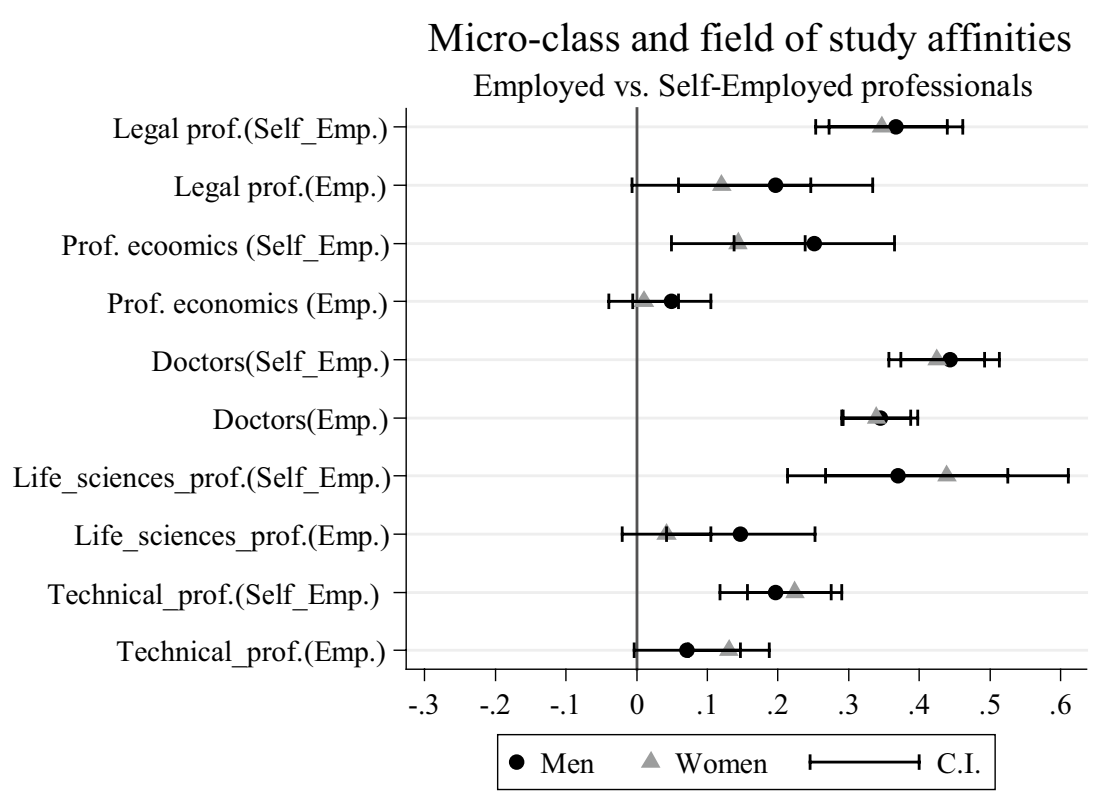

Fig. 5 AME of affinities within a professional domain from a multinomial logistic regression model of the probability of graduating in technical fields, law, medicine, pharmacy and veterinarian, economics, according to gender, and differentiating between employed and self-employed professionals fathers (ref. cat. working-class V-VIIab). Estimates are at net of controls (age, parental education, nationality, geographical area). Black dots denote the AME of social classes for men, and grey triangles denote the AME of social class for women. Black lines denote $95 \%$ confidence intervals. Source: ISTAT-Sbocchi Professionali dei Laureati (2011)

fathers' micro-class position and increases the risks of children with different social background, defined as outsiders, to enter in these professions (Weeden, 2002).

Results presented in Fig. 5 test the last hypothesis on self-employed professions. ${ }^{18}$ These results provide new insights into micro-dynamics of social reproduction among licensed professionals. In each licensed profession, the children of self-employed professionals are more inclined to graduate in the same field of study as their fathers than children of employed professionals. This is also true for children of self-employed professionals in economics. Even if accountancy is a dual entry-routes profession, the affinity between the micro-class of the father and economics as their children's discipline of choice is stronger. ${ }^{19}$ This can be interpreted as a strategic ploy to inherit the father's business ${ }^{20}$ since administrative skills and related competencies in economics are crucial for the running of a professional practice.

\footnotetext{
18 Figure 5 shows results from Model 9 and Model 10. The results of these regressions are reported in tabular form in the Online Appendix. Only the affinity between micro-classes of employed and self-employed fathers and various fields of study is presented.

19 Children of employed accountants also tend to graduate in law which can be used as an alternative route of entering either accountancy or the legal profession (significance $<0.05$ ).

20 See the Online Appendix-Model 9 and Model 10.
} 
As pointed out in the theoretical framework, self-employed professionals combine the characteristics of employers, which are defined on the basis of property, and professionals, which are defined by different levels of closure. From the above analyses, it is apparent that this combination of characteristics encourages a greater degree of micro-class immobility.

Figure 5 shows once again that the transmission of the professional business is relevant for both men and women. However, it is arguable that gender differences become more visible when considering employed professional fathers. With to the field of study of law, it is of greater importance for men to have an employed lawyer as a father than it is for women (see Pellizzari \& Pica, 2011). A similar pattern comes to light when the affinities of pharmacy and veterinarian are considered. These results are in line with those of Tousijn (1979) and Santoro (1998). No significant AME are found for children of employed accountants when considering economics. With respect to architecture and engineering, it is more relevant to have a father employed as a technical professional for women than it is for men.

Finally, with respect to medicine, the employment situation of the father does not make any difference. This is true for both men and women. In this case, the specific structure of the medical professions has to be considered, starting with the important role played by the public sector.

\section{Summary and conclusion}

Bridging the gap between theories of social closure and credentialism, and occupational class theory, has proven useful to understanding the effect of social origins on education, specifically in the case of professional groups. Employing a micro-class approach has revealed the extent to which the educational attainments of children from the professionals are influenced by their parents' professional domains. Indeed, graduation in a specific field is the first barrier to entry into a licensed profession. Professions are understood as a source of class formation, and acquired characteristics—-such as educational credentialsare more likely to cause social exclusion, than ascribed criteria, like gender. Accordingly, the analyses indicate that children of licensed professionals are more inclined to graduate in a field of study that is connected to with the father's profession; that this tendency is stronger among children of self-employed professionals; and that it applies to both men and women.

Deregulation of liberal professions in Italy has been central in many recent public and political debates. This article contributes to this debate by offering a better understanding of micro-level dynamics in the professionals' social reproduction also in terms of a statistical support. These micro-level processes may have strong implications for policy interventions, because they highlight levels of social exclusion related to intergenerational social immobility in the regulated professional employment. The analysis of these results reveals that professional closure enhances the economic profitability of one's professions, especially when there is a transfer of professional business assets between professionals and their children; it incentivises the children of professionals to follow in their parents' footsteps. On the other hand, barriers limiting access to a university education, professional training, and state-level qualifying examinations increase the costs and risks of failure for outsiders. Thus, a progressive harmonization of professional entry market regulation should be considered as a starting point to incentivize social fluidity that can be defined as a modern indicator of social justice. 
Previous social mobility studies, especially in Italy, ignored the micro-dynamics of the intergenerational transmission of social positions, and most studies on licensed professionals have been profession specific. Ours is one of a handful studies that has used a microclass approach to capture the micro-level dynamics of professionals social reproduction and compare the meso- and micro-classes of social origins within the upper class. At the aggregate level, children of professionals behave more like the children of higher managers and larger entrepreneurs. The whole picture changes thanks to a micro-class approach, especially when it comes to highly regulated professions. Moreover, exchanges between micro-classes of professionals, which are captured at the meso-class level, do not occur very often. Cultural proximity has only been noted for architecture and children of engineers and for law and children of professionals in economics. However, there is no specific affinity between the children of self-employed accountants and law. The additional specification of employed and self-employed professional fathers highlights the importance of the inheritance of the professional business. Transfer of property increases the odds of children of both genders following in their fathers' footsteps in each of these liberal professions. Thus, when horizontal inequalities within higher education are taken onto account, considering self-employed professionals as a separate category has proven useful.

Finally, future research should employ a micro-class approach to investigate the origin-destination association and consequently to link the level of intergenerational microclass immobility with market-entry regulations professional services. More research addressing the role of mothers in the professional positions and its impact on educational stratification is also needed. This can create a more comprehensive framework, one that improves our understanding of the effect that social class of origin on educational attainments. Indeed, mothers can play a role for daughters' educational and occupational outcomes even if in this study the father's micro-class position has been proven relevant for daughters' labour market outcomes as well.

Supplementary Information The online version contains supplementary material available at https://doi. org/10.1007/s10734-021-00701-y.

Funding Open access funding provided by University of Turku (UTU) including Turku University Central Hospital. L.R. gratefully acknowledges funding from the Academy of Finland for NEFER (decision 321264) and the INVEST research flagship (decision 320162).

Open Access This article is licensed under a Creative Commons Attribution 4.0 International License, which permits use, sharing, adaptation, distribution and reproduction in any medium or format, as long as you give appropriate credit to the original author(s) and the source, provide a link to the Creative Commons licence, and indicate if changes were made. The images or other third party material in this article are included in the article's Creative Commons licence, unless indicated otherwise in a credit line to the material. If material is not included in the article's Creative Commons licence and your intended use is not permitted by statutory regulation or exceeds the permitted use, you will need to obtain permission directly from the copyright holder. To view a copy of this licence, visit http://creativecommons.org/licenses/by/4.0/.

\section{References}

Abbott, A. (1988). The system of professions: An essay on the division of expert labour. Chicago University Press.

Barbagli, M. and Schizzerotto, A. (1997). Classi, non caste. Mobilità tra generazioni e opportunità di carriera in Italia. Il Mulino, 46(3), 547-557. 
Barone, C. (2005). È possibile spiegare le disuguaglianze di apprendimento mediante la teoria del capitale culturale? Polis, 19(2), 173-202.

Barone, C. (2011). Some things never change: gender segregation in Higher Education across eight countries and three decades. Sociology of Education, 84(2), 157-176.

Barone, C., Luijkx, R., \& Schizzerotto, A. (2010). Elogio dei grandi numeri: il lento declino delle disuguaglianze nelle opportunità di istruzione in Italia. Polis, 24(1), 5-34.

Barone, C., \& Schizzerotto, A. (2011). Career mobility, education, and intergenerational reproduction in five European societies. European Societies, 13(3), 377-400.

Blau, P. M., \& Duncan, O. G. (1967). The American Occupational Structure. Free Press.

Blossfeld, H. P., \& Shavit, Y. (1993). Persistent inequality: A comparative study of educational attainment in thirteen countries. Westview Press.

Bourdieu, P. (1974). Education, opportunity, and social inequality: Changing prospects. Western Society.

Bourdieu, P. (1977). Cultural reproduction and social reproduction. In J. Karabel \& A. H. Halsey (Eds.), power and ideology in education (pp. 487-511). Oxford University Press.

Bourdieu, P. (1979). La distinction: Critique sociale du jugement, Paris, Minuit;trad. it. La distinzione: Critica sociale del gusto. Il Mulino, 1983.

Bourdieu, P. (1986). The forms of capital. In J. G. Richardson (Ed.), Handbook of Theory and Research for the Sociology of Education (pp. 241-258). Greenwood Press.

Bourdieu, P., \& Passeron, J. C. (1977). Reproduction in education, society, and culture. Sage.

Breen, R. (2004). Social mobility in Europe. Oxford University Press.

Breen, R., \& Goldthorpe, J. H. (1997). Explaining educational differentials: Towards a formal rational action theory. Rationality and Society, 9(3), 275-305.

Breen, R., \& Jonsson, J. O. (2000). Analyzing Educational careers: A multinomial transition model. American Sociological Review, 65(5), 754-772.

Breen, R., \& Muller, W. (2020). Education and intergenerational social mobility in Europe and the United States. Stanford University Press.

Breen, R., \& Yaish, M. (2006). Testing the Breen-Goldthorpe model of educational decision making. In S. L. Morgan, D. B. Grusky, \& G. S. Fields (Eds.), Social and Economic Mobility Frontiers (pp. 232-258). Stanford University Press.

Bukodi, E., \& Goldthorpe, J. (2018). Social mobility and education in Britain: Research, politics and policy. Cambridge University Press.

Checchi, D. (2010). Immobilità diffusa: perché la mobilità intergenerazionale è così bassa in Italia. Il Mulino.

Chiesi, A. M. (1997). Lavori e professioni. Caratteristiche e mutamenti dell'occupazione in Italia.

Chiesi, A. M. (2008). L'origine sociale nel successo dei laureati AlmaLaurea in «X Rapporto sulla condizione occupazionale dei laureati. Formazione universitaria ed esigenze del mercato del lavoro», Il Mulino, 2008.

Collins, R. (1971). Functional and conflict theories of educational stratification. American Sociological Review, 36(6), 1002-1018.

Collins, R. (1975). Conflict sociology: Toward an explanatory science. Academic Press.

Collins, R. (1979). The Credential Society: An Historical Sociology of Education and Stratification. Academic Press.

Erikson, R., \& Goldthorpe, H. (1992). The Constant Flux. Oxford University Press.

Fabbri, F., \& Rossi, N. (1997). Caste, non classi. Una società immobile. Il Mulino, 7(1), 110-116.

Gambetta, D. (1987). Were they pushed or did they jump? Individual decision mechanisms in education, Cambridge University Press (trad. It). Per amore o per forza? Le decisioni scolastiche individuali. Il Mulino, 1990.

Gamoran, A. (2001). American schooling and educational inequality: A forecast for 21 st century. Sociology of Education, 69(4), 290-307.

Gamoran, A., \& Mare, R. D. (1989). Secondary school tracking and educational inequality: Compensation, reinforcement, or neutrality? American Journal of Sociology, 94(5), 1146-1183.

Goldthorpe, J. H. (2002). Occupational sociology, yes: Class analysis, No: Comment on Grusky and Weeden's Research Agenda. Acta Sociologica, 45(3), 211-217.

Grusky, D. B. (2005). Foundations of a neo-durkheimian class analysis. In E. O. Wright (Ed.), Approaches to Class Analysis (pp. 51-81). Cambridge University Press.

Grusky, D. B., \& Sørensen, J. B. (1998). Can class analysis be salvaged? American Journal of Sociology, 103(5), 1187-1234.

Grusky, D. B., \& Sørensen, J. B. (2001). Are There Big Social Classes? In D. B. Grusky (Ed.), Social Stratification: Class, Race, and Gender (pp. 183-194). Westview Press. 
Grusky, D. B., \& Weeden, K. A. (2001). Decomposition without death: A research agenda for a new class analysis. Acta Sociologica, 44(3), 203-218.

Grusky, D. B., \& Weeden, K. A. (2011). Is market failure behind the takeoff in income inequality? The inequality reader: Contemporary and foundational readings in race, class, and gender. Boulder.

Hansen, M. N. (1997). Social and economic inequality in the educational career: Do the effects of social background characteristics decline? European Sociological Review, 13(3), 305-321.

Jackson, M., Luijkx, R., Pollak, L.-A., Vallet, \& Van de Werfhorst, H. G. (2008). Educational fields of study and the intergenerational mobility process in comparative perspective. International Journal of Comparative Sociology, 49(4-5), 369-388.

Jonsson, J. O., Grusky, D. B., Di Carlo, M., Pollak, R., \& Brinton, M. C. (2009). Microclass mobility: Social reproduction in four countries. American Journal of Sociology, 114(4), 977-1036.

Larson, M. S. (1977). The rise of professionalism. University of California Press.

Murphy, R. (1988). Social closure: The theory of monopolization and exclusion. Clarendon Press.

Parkin, F. (1971). Class inequality and political order: social stratification in capitalist and communist societies. Praeger.

Parkin, F. (1974). The social analysis of class structure. Tavistock.

Parkin, F. (1979). Marxism and class theory: A bourgeois critique. Columbia University Press.

Patterson, I., Fink, M., Ogus, A. (2003).The economic impact of regulation in the field of liberal professions in different member states, Regulation of the Professional Service. Study for the European Commission, DG Competition, www.ec.europa.eu

Pellizzari, M. and Pica, G. (2011). Liberalizing professional services: Evidence from Italian lawyers, IGIER Working Paper, n. 372.

Pellizzari, M., \& Orsini, J. (2012). Dinastie d'Italia: Gli ordini tutelano davvero i consumatori? Università della Bocconi Editore.

Pisati, M. (2003). L'analisi dei dati. Tecniche quantitative per le scienze sociali. Il Mulino.

Ruggera, L. (2016). Professioni licenziate e lauree conseguite: un'analisi delle micro dinamiche di riproduzione intergenerazionale in Italia. Polis, 1(2016), 61-86.

Ruggera, L., \& Barone, C. (2017). Social closure, micro-class immobility and the intergenerational reproduction of the upper class: a comparative study. The British Journal of Sociology, 68(2), 194-214.

Santoro, M. (1998). Notai. Storia sociale di una professione in Italia 1861-1940. Il Mulino.

Schizzerotto, A. (1993). La porta stretta: classi superiori e processi di mobilità. Polis, 7(1), 15-43.

Sørensen, A. B. (1996). The Structural Basis of Social Inequality. American Journal of Sociology, 101(5), $1333-1365$.

Sørensen, J. and Grusky, D. B. (1998). The Structure of Career Mobility in Microscopic Perspective, in Social Differentiation and Social Inequality: Essays in Honor of John Pock, (eds.) J. N. Baron and D. B. Grusky (pp. 83-114) Westview Press.

Sørensen, A. B. (2000). Toward a sounder basis for class analysis. American Journal of Sociology, 105(6), $1523-1558$.

Stocké, V. (2007). Explaining educational decisions and effects of families' social class position: an empirical test of the Breen-Goldthorpe model of educational attainment. European Sociological Review, 23(4), 505-519.

Tousijn, W. (1979). Sociologia delle professioni. Il Mulino.

Tousijn, W. (1987). Le libere professioni in Italia. Il Mulino.

Van de Werfhorst, H. G. (2002). A detailed examination of the role of education in intergenerational social class mobility. Social Science Information, 41(3), 407-438.

Van de Werfhorst, H. G., \& Luijkx, R. (2010). Educational field of study and social mobility: Disaggregating social origin and education. Sociology, 44(4), 695-715.

Weber, M. (1922).Wirtschaft und Gesellschaft, Tübingen, Mohr, trad. Engl. Economy and society: An outline of interpretative sociology. University of California Press, 1978.

Weeden, K. A. (2002). Why do some occupations pay more than others? Social closure and earnings inequality in the United States. American Journal of Sociology, 108(1), 55-101.

Weeden, K. A., \& Grusky, D. B. (2005). The case for a new class map. American Journal of Sociology, 111(1), 141-212.

Weeden, K. A., \& Grusky, D. B. (2012). The three worlds of inequality. American Journal of Sociology, 117(6), 1723-1785.

Publisher's note Springer Nature remains neutral with regard to jurisdictional claims in published maps and institutional affiliations. 